\title{
FABRICAÇÃO DE MÁQUINAS, APARELHOS E MATERIAIS ELÉTRICOS: UMA ANÁLISE PRELIMINAR DA PRODUTIVIDADE
}

\author{
Carolina Silvestri Cândido
}

\section{RESUMO}

Inovação e produtividade são conceitos econômicos bastante próximos. Pela literatura econômica, a produtividade decorre da inserção da técnica moderna nos diversos aspectos produtivos, porém, ganhos de produtividade podem decorrer de fatores diversos que transcendem a inovação, pois a produtividade é analisada como resultado da competitividade sistêmica. O setor industrial de fabricação de máquinas, aparelhos e materiais elétricos é relevante nas estruturas industriais. É um setor receptivo ao progresso técnico, porém, analisando seus grupos industriais, verifica-se lógica distinta entre eles em termos de agregação de valor e dinâmica concorrencial. A produtividade do setor é inferior à média nacional e da indústria de transformação, assim como o investimento em aquisição de ativos imobilizados. Em contrapartida, a inovação do setor se destaca, nos diversos aspectos avaliados. Assim, compreende-se que a análise comparativa da produtividade deve se encerrar ao âmbito setorial, a comparação com a média da indústria nacional e de transformação pode distorcer os resultados.

Innovation and productivity are two very close economic concepts. To the economic literature, productivity comes from the integration of modern technology in various production aspects, however, productivity gains may result from several factors that transcend innovation, productivity must be analyzed as a result of systemic competitiveness. The industrial sector of manufacture of machinery, appliances and equipment is relevant to the industrial structures. It is a receptive sector to technical progress, however, analyzing its industrial groups, there are distinct logics between them in terms of added value and competitive dynamics. The sector's productivity is lower than the national average and the processing industry, as well as investment in acquisition of fixed assets. In contrast, the industry's innovation stands out in different aspects evaluated. Thus, it is understood that comparative analysis of productivity should be done considering sectoral level analysis; the comparison to the average of the domestic and processing industry can distort the results

Palavras-chave: produtividade, inovação, fabricação de máquinas, aparelhos e materiais elétricos.

Keywords: productivity, innovation , manufacturing machinery, appliances and equipment .

\section{INTRODUÇÃO}

A inovação é posicionada como central no processo de desenvolvimento econômico. Ela é cumulativa, qualitativa e apresenta seus microfundamentos na análise neoschumpeteriana das empresas. Assim, compõem a realidade da inovação os processos de rotina, busca e seleção. A inovação inaugura paradigmas tecnológicos e assim relaciona-se com a mudança estrutural, fomentando um processo de destruição criadora. 
A produtividade resulta da competitividade, e, por vezes, confunde-se com inovação. Inovação e produtividade apresentam íntima relação, pois inovar pode gerar ganhos substanciais de produtividade. Porém, é possível fomentar ganhos de produtividade por vias que não da inovação, e também inovar sem resultar em aumentos da produtividade. Assim, é preciso conceituar inovação e produtividade e se aprofundar nos fios condutores que as interrelacionam.

O setor de fabricação de máquinas, aparelhos e materiais elétricos apresenta uma variedade de grupos que o compõem, assim, sua dinâmica interna nem sempre é homogênea. Em comparação com a indústria de transformação nacional, este setor detém $3 \%$ do Pessoal Ocupado (PO), 1,6\% do número de empresas, 3,1\% do Valor Bruto da Produção Industrial (VBPI) e 3\% do Valor da Transformação Industrial (VTI) da indústria de transformação nacional.

O objetivo do presente artigo é realizar uma análise quantitativa da produtividade da fabricação de máquinas, aparelhos e materiais elétricos, em comparação com a indústria total e de transformação brasileiras. O principal enfoque é nas relações com investimento e inovação, visando verificar se estes apresentam relação positiva com a produtividade observada.

\section{INOVAÇÃO: uma abordagem Schumpeteriana}

Schumpeter inaugura na economia a era da inovação, ao posiciona-la como central no processo de desenvolvimento econômico. A inovação é causa das transformações nas indústrias, estruturas produtivas, economia mundial, assim, como também, é consequência das interações das novas combinações que determinam os novos produtos, novos métodos de produção, novas fontes de matéria-prima, exploração de novos mercados e novas formas de organizar as empresas. Vista como derivada de um processo qualitativo e cumulativo de transformação, é também a inovação que condiciona os ciclos econômicos. Neste contexto, a presente seção apresenta a ideia schumpeteriana referente à inovação e aspectos proeminentes da abordagem neoschumpeteriana.

A relação entre inovação e mudança industrial é tema central no trabalho de Schumpeter. A inovação, como um processo de destruição criadora ou um processo de acumulação criadora é apresentada como fator pertinente à evolução das indústrias e inerente ao processo de transformação econômica. A inovação é intimamente relacionada com o surgimento, crescimento e declínio das indústrias, que marcam historicamente o desenvolvimento do capitalismo. Inovações como historicamente agrupadas em setores específicos, desenvolvimento industrial e transformação associados ao surgimento e crescimento de diferentes setores, concorrência dinâmica como a luta entre as empresas que introduzem novas tecnologias e produtos e os operadores históricos que incidem sobre as tecnologias existentes são temas tratados e que fazem os nexos entre inovação e indústria (MALERBA, 2006).

A mensagem original de Schumpeter sobre a inovação a colocada no centro da evolução das indústrias e transformação estrutural em várias direções. A agenda de pesquisa neoschumpeteriana, compartilhar dois elementos centrais: a reconhecimento do papel essencial da inovação nos processos económicos e a necessidade de usar uma análise dinâmica. O pensamento neo-schumpeterianos apresenta os microfundamentos existentes no processo de destruição criadora de Schumpeter onde se quebra um ciclo econômico para o surgimento de um novo, pautado sob novas bases. O novo se sobrepõe ao velho, via 
concorrência, e é nesse processo que ocorre o desenvolvimento socioeconômico (MALERBA, 2006).

Tecnologia e inovação estão intimamente relacionadas. A tecnologia é proveniente da oferta, como criadora de novas necessidades e não como forma de suprir uma necessidade já existente. A ciência e a tecnologia desenvolvem-se independentemente do funcionamento do sistema econômico, seus avanços estão no âmbito das pesquisas e da ciência, restritos aos cientistas e engenheiro. A demanda também desempenha papel no processo tecnológico estimulando o investimento, a invenção e o patenteamento. A tecnologia acaba se consolidando como um pool de conhecimentos capaz de responder de forma rápida e flexível aos estímulos da demanda, ou seja, capaz de reagir aos movimentos do mercado suprindo e criando novas necessidades, desta forma o processo inovativo ocorre com a interação científica, tecnológica e econômica (NELSON e WINTER, 1982).

A inovação inaugura paradigmas tecnológicos que representam modelos ou padrões de solução para problemas tecnológicos selecionados, baseados em princípios selecionados da ciências naturais e em materiais tecnológicos selecionados. A tecnologia envolve a solução de problemas e soluções inovadoras exigem descoberta e criatividade, um paradigma tecnológico define contextualmente a necessidade que deve ser saciada, os princípios científicos que poderão ser utilizados para tal, o material tecnológico a ser usado, ou seja, define um padrão de soluções de problemas tecnológicos selecionados baseados na eleição de princípios derivados das ciências naturais conjunto com regras específicas para se adquirir um novo conhecimento protegendo-o, sempre que possível, contra a rápida difusão do mesmo para os competidores (DOSI, 1988).

Os paradigmas tecnológicos, nos termos definidos anteriormente, definem uma trajetória tecnológica que se conceitua como atividade de processos tecnológicos que ocorrem durante trade-offs tecnológicos e econômicos definidos por um paradigma tecnológico, ou seja, representam a atividade de resolução de problemas tecnológicos e que podem ser representadas pelo avanço nos múltiplos trade-off entre as variáveis que o paradigma considera relevante. Nada mais é que os caminhos do avanço tecnológico (DOSI, 1998).

As mudanças tecnológicas podem ocorrer em vistas da capacidade de resposta do paradigma, elas se mostram irregulares no tempo, com alternância entre períodos de ruptura e períodos em que o progresso técnico avança de forma contínua e previsível. Com o andar da trajetória tecnológica, se reduz progressivamente a oportunidade de mudança tecnológica e se induz a inovação. Tais pressões e estímulos dão incitações a esforços científicos e tecnológicos que conduzem à aparição de um novo paradigma. As mudanças tecnológicas se associam às alterações da técnica no percurso da trajetória tecnológica, mas sem que haja alteração do paradigma tecno-produtivo (DOSI, 1998).

As mudanças tecnológicas têm como determinante os insumos científicos que passam a ter papel relevante na busca pela inovação, as atividades de P\&D que passam a fazer parte da rotina empresarial ao se ter a inovação como investimento de altos risco e rendimento cunhada nos planejamentos de longo prazo empresariais, o conhecimento tácito existente nos trabalhadores, a crescente formalização institucional da investigação, o estado da tecnologia vigente e os percalços já trilhados pela empresa (DOSI, 1998).

A inovação é capaz de alterar as estruturas de mercado, através do acirramento do processo concorrencial, fomentado pela inovação, faz-se com que ao determinar-se a inovar, a empresa se ponha, ao esquematizar seus esforços inovativos, em vantagem em comparação com as outras empresas. A inovação permite geração temporária de monopólios e aumento do market share em relação aos outros concorrentes no mercado, desta forma, a empresa inovadora consegue desfrutar dos lucros extraordinários advindos da inovação e assim criar 
condições de maior sobrevivência no mercado. A concretização da inovação reduz o número de concorrentes, pois não são todos que podem fazer frente ao processo inovativo, e assim se aumenta o grau de oligopolização nos mercados (DOSI, 1998).

As rotinas empresariais representam o estoque de conhecimento organizacional específico adquirido. O processo de busca da inovação tem caráter irreversível, tem caráter contingente frente a trajetória vigente e apresenta incertezas. O processo de busca pode modificar rotinas e são condicionados por elas, eles também podem ser rotinizados. Os processos internos de busca baseiam-se na ampliação da base de conhecimento científica e tecnológico e no desempenho passado de busca inovativa, assim como a coerência da diversidade dos produtos da empresa e sua capacidade organizacional, os processos externos são condicionados pelo ambiente econômico que a empresa se insere, assim como ao paradigma tecnológico vigente, fontes de informações externas e comportamento dos concorrentes. Na seleção da inovação é importante se levar em conta que os sinais de mercado são assimétricos e se vinculam à posição da empresa frente à fronteira tecnológica assim como às expectativas de rentabilidade da inovação (DOSI, 1998).

Na busca pela inovação o conhecimento é de suma importância, pois é o conhecimento que torna a inovação possível. É possível se adquirir conhecimento através de quatro formas de processo de aprendizagem, learning by searching, learning by doing, learning by using e learning by interacting. No primeiro se aprende através da pesquisa, este se encontra intimamente vinculado aos departamentos empresariais de $\mathrm{P} \& \mathrm{D}$. $\mathrm{O}$ segundo se aprende fazendo, está relacionado ao conhecimento tácito das empresas, se baseia na experiência, capacidade e conhecimento do trabalhador para promover mudanças técnicas, se relaciona a inovações incrementais. O terceiro é referente à aprendizagem pelo uso, ocorre no decorrer do uso e consumo de um bem, não possibilita que se preveja com antecedência o resultado da inovação, surge da troca de informações entre usuário e produtor. O quarto diz respeito ao aprender através da interação e é a combinação dos aprendizados pela produção e uso, nele fornecedores interagem gerando fluxos de informações tecnológicas e parcerias para a inovação, há a transmissão de conhecimento tácito (DOSI, 1998).

\section{INOVAÇÃO E PRODUTIVIDADE: inserção da técnica moderna}

Importa pontuar a relação existente entre inovação e produtividade, visto que ambos os temas se inter-relacionam e determinam em diversas direções. Ressaltada a importância da inovação, a produtividade também é condicionada por esta e o comportamento da firma próinovação determina, nos diversos âmbitos, sua produtividade, conjunto a outros fatores também importantes. Neste contexto, apresentar a relação entre inovação e produtividade e analisar o comportamento da firma inovadora é o objetivo desta seção.

A empresa apresenta papel como elemento que introduz as inovações no mercado. As invenções aderentes ao processo produtivo se inserem nele com o intuito de gerar ganhos de produtividade, tratando-se das inovações de processo. Ou, são incorporadas à concepção de produtos visando agregação de valor. Também são inseridas nas formas de comercializar e nas diversas maneiras de relacionamento com o cliente também visando agregação de valor a produtividade, dentre outas. Em síntese, a lógica competitiva anuncia que a transformação de insumos e técnicas produtivas em novos processos e produtos, via inovação, resulta em ganhos de produtividade (STEINGRABER, 2009).

O empresário inovador schumpeteriano se arrisca ao lançar inovações no mercado, visando lucros extraordinários derivados do processo de inovação e existente devido ao monopólio temporário que criam as ondas primárias inovativas. Neste contexto, sendo o 
empresário o agente que carrega consigo o gérmen da inovação, a empresa é seu lócus e sua efetivação se dá no mercado, uma vez que encontra a demanda necessária para gerar resultado (STEINGRABER, 2009).

Com a onda primária da inovação vem as ondas secundárias da imitação, uma vez que, à medida que ocorre o processo de inovação, ocorrem também os processos de imitação. A imitação condiciona a assimilação da inovação na coletividade, configurando um processo de destruição criativa, pois os processos econômicos baseados no velho vão sendo substituídos pelo novo, gerando assim abandono de técnicas e atividades produtivas que se tornam obsoletas.

A produtividade é estimulada pela competição capitalista, que dá vasão ao processo de progresso técnico e assim inovação. O processo de progresso técnico passa, primeiramente, pela invenção, que é exógena à empresa e apresenta incertezas em relação a seu tempo de maturação e potencial econômico. Porém, a capacidade inventiva tem uma trajetória que exalta o estoque de conhecimento da sociedade, apresentando assim característica cumulativa. A inovação se conceitua na aplicação econômica da invenção, que, ao gerar resultado, apresenta aderência à produtividade.

A inovação ao condicionar a produtividade contextualizada em um processo concorrencial demonstra seu caráter evolucionário. A adoção de um paradigma tecnológico impõe as formas de se produzir, comercializar e competir, neste contexto, as empresas se inserem em um processo de seleção natural e de transformações adaptativas ao novo padrão vigente de mercado. O caráter evolucionário determina a seleção natural das empresas com maior capacidade adaptativa (NELSON e WINTER, 1982).

O impacto da inovação sobre a indústria e o crescimento econômico ocorre via produtividade, sendo a produtividade a medida de eficiência pela qual as empresas transformam insumos em produtos e a maneira como este produto encontra a demanda no mercado. Assim, importa compreender os fatores que determinam a inovação e assim sua consequência na produtividade e nos agentes econômicos, gerando vantagens.

Neste contexto, definir os determinantes da inovação propicia saber em qual medida a produtividade é influenciada. Assim a inovação passa a ser observada como um aspecto complexo que incorpora diversos fatores de mensuração principalmente das atividades tecnológicas. Os fatores da inovação é que conduzem ao aumento final da produtividade como consequência do processo de inovação, sendo estes fatores usualmente medidos na pesquisa e desenvolvimento (P\&D), patentes e mão de obra qualificada, bem como o entendimento dos fatores externos, como a mudança organizacional, a cooperação ou financiamento da P\&D.

A linha que separa a produtividade da introdução de inovação na indústria é tênue, outros fatores, além da inovação, também determinam a produtividade, como a exploração de economias de escala, que podem aumentar a produtividade sem a introdução de mudança técnica, além de que nem sempre uma inovação causa um aumento imediato na produtividade.

Os modelos schumpeterianos têm buscado identificar os fatores específicos de aprendizado e interação da empresa com os fatores de inovação presentes na função de produção do conhecimento da empresa, sendo que o capital humano o causador das inovações. Por este raciocínio, o aumento da produtividade não passa apenas pelo maior acúmulo de capital, mas também pelo aprendizado tecnológico e ampliação da capacidade de inovação que variam entre as empresas (STEINGRABER, 2009).

Em resumo, a relação entre inovação e produtividade é tênue. Nem toda a produtividade é explicada pela inovação, assim como a inovação pode não resultar em ganhos de produtividade. Porém, muito da produtividade é determinada pela inovação, uma vez que 
os fatores que determinam a inovação também estão no cerne da produtividade. A íntima relação entre produtividade e inovação também se evidencia uma que ambas são condicionadas à mesma lógica concorrencial e processo evolucionário, respondendo assim aos mesmos estímulos determinísticos.

4. O SETOR DE MÁQUINAS, APARELHOS E MATERIAIS ELÉTRICOS: breve análise concorrencial e quantitativa.

Posicionar o setor de fabricação de máquinas, aparelhos e materiais elétricos é o principal objetivo da presente seção. Neste sentido, este será caracterizado como dados relacionados ao pessoal, produção, investimento e inovação. O setor será situado em relação à sua representatividade nacional, com dados normalizados pelo pessoal ocupado ou número de empresas

A análise quantitativa do setor de fabricação de máquinas, aparelhos e materiais elétricos divide-se em quatro grandes grupos de comparação: a indústria total, indústria de transformação, fabricação de máquinas, aparelhos e materiais elétricos e seus grupos. Primeiramente, a participação em relação à indústria total é apresentada, e, em seguida, a participação de cada grupo de atividade econômica no total da fabricação de máquinas, aparelhos e materiais elétricos.

4.1 Dados relativos ao Pessoal da Fabricação de máquinas, aparelhos e materiais elétricos

Seguindo a lógica apontada acima, a Tabela 1 apresenta o pessoal ocupada na indústria total, de transformação, fabricação de máquinas, aparelhos e materiais elétricos e seus grupos. A participação do setor estudado na indústria total se mantem estável em 3\%, de 2007 a 2013, com pequeno crescimento de 0,2 pontos percentuais. Como a indústria de transformação representa $98 \%$ da indústria total, a participação em relação a esta é muito parecida, também estável em 3\%, de 2007 a 2013.

Adentrando nos grupos que compõem a fabricação de máquinas, aparelhos e materiais elétricos, aqueles de maior representatividade são: fabricação de geradores, transformadores e motores elétricos, fabricação de equipamentos para distribuição e controle de energia e fabricação de eletrodomésticos. A fabricação de eletrodomésticos reduz sua participação em relação à indústria da fabricação de máquinas, aparelhos e materiais elétricos em 1 ponto percentual, comparando-se 2007 e 2013, finalizando a séria com 25\% do pessoal ocupado. A fabricação de equipamentos para distribuição e controle de energia mantem sua participação estável em $27 \%$, enquanto a fabricação de geradores, aparelhos e materiais elétricos eleva sua participação em 2 pontos percentuais, também obtendo 27\% do pessoal ocupado no setor em 2013.

Tabela 1: Pessoal Ocupado em 31/12 - Indústria total, transformação e Fabricação de máquinas, aparelhos e materiais elétricos e seus grupos (2007 - 2013)

\begin{tabular}{|l|c|c|c|c|c|c|c|}
\hline & $\mathbf{2 0 0 7}$ & $\mathbf{2 0 0 8}$ & $\mathbf{2 0 0 9}$ & $\mathbf{2 0 1 0}$ & $\mathbf{2 0 1 1}$ & $\mathbf{2 0 1 2}$ & $\mathbf{2 0 1 3}$ \\
\cline { 2 - 7 } Total & $100 \%$ & $100 \%$ & $100 \%$ & $100 \%$ & $100 \%$ & $100 \%$ & $100 \%$ \\
\hline C Indústrias de transformação & $98 \%$ & $98 \%$ & $98 \%$ & $98 \%$ & $98 \%$ & $97 \%$ & $97 \%$ \\
\hline 27 Fabricação de máquinas, aparelhos e materiais elétricos & $3 \%$ & $3 \%$ & $3 \%$ & $3 \%$ & $3 \%$ & $3 \%$ & $3 \%$ \\
\hline 27.1 Fabricação de geradores, transformadores e motores elétricos & $25 \%$ & $26 \%$ & $25 \%$ & $26 \%$ & $27 \%$ & $27 \%$ & $27 \%$ \\
\hline 27.2 Fabricação de pilhas, baterias e acumuladores elétricos & $5 \%$ & $5 \%$ & $5 \%$ & $5 \%$ & $5 \%$ & $4 \%$ & $5 \%$ \\
\hline
\end{tabular}




\begin{tabular}{|c|c|c|c|c|c|c|c|}
\hline $\begin{array}{l}27.3 \text { Fabricação de equipamentos para distribuição e controle de } \\
\text { energia elétrica }\end{array}$ & $27 \%$ & $30 \%$ & $26 \%$ & $27 \%$ & $26 \%$ & $26 \%$ & $27 \%$ \\
\hline $\begin{array}{l}\text { 27.4 Fabricação de lâmpadas e outros equipamentos de } \\
\text { iluminação }\end{array}$ & $8 \%$ & $6 \%$ & $6 \%$ & $6 \%$ & $6 \%$ & $6 \%$ & $6 \%$ \\
\hline 27.5 Fabricação de eletrodomésticos & $26 \%$ & $24 \%$ & $29 \%$ & $25 \%$ & $25 \%$ & $27 \%$ & $25 \%$ \\
\hline $\begin{array}{l}\text { 27.9 Fabricação de equipamentos e aparelhos elétricos não } \\
\text { especificados anteriormente }\end{array}$ & $9 \%$ & $9 \%$ & $10 \%$ & $10 \%$ & $11 \%$ & $10 \%$ & $11 \%$ \\
\hline
\end{tabular}

Fonte: PIA - IBGE (2015)

Importa conhecer a realidade do setor, em termos de número de empresas. A participação em relação ao pessoal ocupado é mais elevada, considerando-se o número de empresas do setor em foco. A fabricação de máquinas, aparelhos e materiais elétricos manteve estável sua participação em relação à indústria de transformação nacional em 1,6\%. A diferença entre a participação em termos de número de empresas e pessoal ocupado sinaliza que o porte das empresas do setor deve ser, em média, superior ao nacional.

Os grupos que compõem o setor apresentam participação em termos de número de empresas mais homogênea que aquela observada no pessoal ocupado, como é possível observar na Tabela 2. Em 2013, os grupos fabricação de geradores, transformadores e motores elétricos, fabricação de equipamentos para distribuição e controle de energia elétrica, fabricação de lâmpadas e outros equipamentos de iluminação, fabricação de eletrodomésticos e aparelhos elétricos não especificados anteriormente, apresentam participação acima de 10\%.

Tabela 2: Número de empresas (unidades) - Indústria total, transformação e Fabricação de máquinas, aparelhos e materiais elétricos e seus grupos (2007 - 2013)

\begin{tabular}{|l|c|c|c|c|c|c|c|}
\hline \multirow{2}{*}{ Total } & $\mathbf{2 0 0 7}$ & $\mathbf{2 0 0 8}$ & $\mathbf{2 0 0 9}$ & $\mathbf{2 0 1 0}$ & $\mathbf{2 0 1 1}$ & $\mathbf{2 0 1 2}$ & $\mathbf{2 0 1 3}$ \\
\hline & $100 \%$ & $100 \%$ & $100 \%$ & $100 \%$ & $100 \%$ & $100 \%$ & $100 \%$ \\
\hline C Indústrias de transformação & $98 \%$ & $98 \%$ & $98 \%$ & $98 \%$ & $98 \%$ & $98 \%$ & $98 \%$ \\
\hline 27 Fabricação de máquinas, aparelhos e materiais elétricos & $1,7 \%$ & $1,5 \%$ & $1,6 \%$ & $1,6 \%$ & $1,6 \%$ & $1,6 \%$ & $1,6 \%$ \\
\hline $\begin{array}{l}\text { 27.1 Fabricação de geradores, transformadores e motores } \\
\text { elétricos }\end{array}$ & $14,0 \%$ & $13,7 \%$ & $12,9 \%$ & $13,6 \%$ & $13,6 \%$ & $13,3 \%$ & $14,0 \%$ \\
\hline 27.2 Fabricação de pilhas, baterias e acumuladores elétricos & $4,1 \%$ & $4,3 \%$ & $3,9 \%$ & $4,0 \%$ & $3,4 \%$ & $3,2 \%$ & $3,2 \%$ \\
\hline $\begin{array}{l}\text { 27.3 Fabricação de equipamentos para distribuição e controle } \\
\text { de energia elétrica }\end{array}$ & $28,9 \%$ & $30,9 \%$ & $30,8 \%$ & $30,2 \%$ & $28,7 \%$ & $33,0 \%$ & $31,4 \%$ \\
\hline $\begin{array}{l}\text { 27.4 Fabricação de lâmpadas e outros equipamentos de } \\
\text { iluminação }\end{array}$ & $18,9 \%$ & $16,6 \%$ & $16,1 \%$ & $16,7 \%$ & $16,0 \%$ & $15,3 \%$ & $15,5 \%$ \\
\hline 27.5 Fabricação de eletrodomésticos & $11,8 \%$ & $9,8 \%$ & $10,4 \%$ & $10,5 \%$ & $10,6 \%$ & $10,6 \%$ & $9,8 \%$ \\
\hline $\begin{array}{l}\text { 27.9 Fabricação de equipamentos e aparelhos elétricos não } \\
\text { especificados anteriormente }\end{array}$ & $22,2 \%$ & $24,6 \%$ & $25,9 \%$ & $25,0 \%$ & $27,6 \%$ & $24,5 \%$ & $26,1 \%$ \\
\hline
\end{tabular}

Fonte: PIA - IBGE (2015)

Em 2013, a participação dos grupos citados foi de 14, 31,4, 15,5 e 26,1\%, respectivamente. Assim, o número de empresas sinaliza para uma estrutura produtividade diversificada, mas para a existência de perfis de porte empresariais distintos, de acordo com o grupo industrial analisado. A Tabela 3 demonstra o supracitado, o porte médio da indústria brasileira, tanto total quanto de transformação é de 46 trabalhadores, já o setor analisado apresenta porte médio superior, sendo que houve aumento do porte empresarial de 2007, quando era de 80 trabalhadores por unidade, para 92 em 2013.

Tabela 3: Porte médio empresarial (pessoal ocupado/número de empresas) - Indústria total, transformação e Fabricação de máquinas, aparelhos e materiais elétricos e seus grupos (2007 - 2013)

Total

\begin{tabular}{|c|c|c|c|c|c|c|}
\hline $\mathbf{2 0 0 7}$ & $\mathbf{2 0 0 8}$ & $\mathbf{2 0 0 9}$ & $\mathbf{2 0 1 0}$ & $\mathbf{2 0 1 1}$ & $\mathbf{2 0 1 2}$ & $\mathbf{2 0 1 3}$ \\
\hline 45 & 45 & 44 & 46 & 46 & 48 & 46 \\
\hline
\end{tabular}




\begin{tabular}{|l|c|c|c|c|c|c|c|}
\hline C Indústrias de transformação & 45 & 45 & 44 & 46 & 45 & 48 & 46 \\
\hline 27 Fabricação de máquinas, aparelhos e materiais elétricos & 80 & 87 & 86 & 90 & 88 & 96 & 92 \\
\hline $\begin{array}{l}\text { 27.1 Fabricação de geradores, transformadores e motores } \\
\text { elétricos }\end{array}$ & 144 & 162 & 170 & 172 & 171 & 194 & 179 \\
\hline 27.2 Fabricação de pilhas, baterias e acumuladores elétricos & 97 & 104 & 104 & 110 & 123 & 127 & 132 \\
\hline $\begin{array}{l}\text { 27.3 Fabricação de equipamentos para distribuição e controle } \\
\text { de energia elétrica }\end{array}$ & 75 & 85 & 72 & 82 & 80 & 77 & 78 \\
\hline $\begin{array}{l}\text { 27.4 Fabricação de lâmpadas e outros equipamentos de } \\
\text { iluminação }\end{array}$ & & & & & & & \\
\hline 27.5 Fabricação de eletrodomésticos & 174 & 214 & 241 & 216 & 205 & 244 & 232 \\
\hline $\begin{array}{l}\text { 27.9 Fabricação de equipamentos e aparelhos elétricos não } \\
\text { especificados anteriormente }\end{array}$ & 32 & 32 & 32 & 36 & 35 & 38 & 39 \\
\hline
\end{tabular}

Fonte: PIA - IBGE (2015)

Dentre os grupos que compõem o setor de máquinas, aparelhos e materiais elétricos a realidade dos portes médios das empresas é diversificada. Enquanto os grupos de fabricação de geradores, transformadores e motores elétricos, fabricação de pilhas, baterias e acumuladores elétricos e fabricação de eletrodomésticos as empresas têm, em média, 179, 132 e 232 trabalhadores alocados, respectivamente, na fabricação de lâmpadas e outros equipamentos de iluminação e fabricação de equipamentos e aparelhos elétricos não especificado anteriormente esta média cai para 34 e 39, respectivamente.

As atividades dos grupos ondo o porte médio é maior são de maior complexidade, contendo maior divisão de tarefas e contingente tecnológico, exigindo um número de trabalhadores superior àquele observado em atividades mais simples.

Em média, 77\% do pessoal ocupado está ligado à produção, tanto na indústria total, quando de transformação e fabricação de máquinas, aparelhos e materiais elétricos. Os grupos de fabricação de pilhas, baterias e acumuladores elétricos e fabricação de lâmpadas e outros equipamentos de iluminação apresentam média superior, de 80\%. De 2007 para 2013, tanto da indústria total quanto de transformação e fabricação de máquinas, aparelhos e materiais elétricos, a participação reduziu em torno de 1,6 pontos percentuais.

Tabela 4: Total de salários, retiradas e outras remunerações (Mil Reais/PO) - Indústria total, transformação e Fabricação de máquinas, aparelhos e materiais elétricos e seus grupos (2007 - 2013)

\begin{tabular}{|l|c|c|c|c|c|c|c|}
\hline & $\mathbf{2 0 0 7}$ & $\mathbf{2 0 0 8}$ & $\mathbf{2 0 0 9}$ & $\mathbf{2 0 1 0}$ & $\mathbf{2 0 1 1}$ & $\mathbf{2 0 1 2}$ & $\mathbf{2 0 1 3}$ \\
\cline { 2 - 7 } Total & 24,31 & 24,44 & 25,71 & 26,70 & 27,71 & 29,17 & 30,58 \\
\hline C Indústrias de transformação & 23,62 & 23,79 & 24,98 & 25,99 & 27,11 & 28,38 & 29,88 \\
\hline 27 Fabricação de máquinas, aparelhos e materiais elétricos & 28,14 & 31,01 & 32,13 & 37,39 & 33,82 & 35,68 & 36,65 \\
\hline 27.1 Fabricação de geradores, transformadores e motores elétricos & 33,81 & 35,14 & 44,00 & 39,14 & 42,26 & 46,95 & 46,49 \\
\hline 27.2 Fabricação de pilhas, baterias e acumuladores elétricos & 24,16 & 24,73 & 26,22 & 27,56 & 29,14 & 30,71 & 31,42 \\
\hline $\begin{array}{l}\text { 27.3 Fabricação de equipamentos para distribuição e controle de } \\
\text { energia elétrica }\end{array}$ & 25,69 & 33,17 & 29,37 & 32,06 & 32,57 & 34,16 & 34,91 \\
\hline 27.4 Fabricação de lâmpadas e outros equipamentos de iluminação & 28,77 & 19,71 & 19,11 & 22,36 & 22,24 & 23,14 & 23,27 \\
\hline 27.5 Fabricação de eletrodomésticos & 28,33 & 31,21 & 30,07 & 49,81 & 32,14 & 30,79 & 35,60 \\
\hline $\begin{array}{l}\text { 27.9 Fabricação de equipamentos e aparelhos elétricos não } \\
\text { especificados anteriormente }\end{array}$ & 20,58 & 22,80 & 24,67 & 29,99 & 29,14 & 31,65 & 28,19 \\
\hline
\end{tabular}

Fonte: PIA - IBGE (2015)

A remuneração média da fabricação de máquinas, aparelhos e materiais elétricos é superior às observadas na indústria total e de transformação. Porém, observando os grupos 
que compõem o setor, a fabricação de geradores, transformadores e motores elétricos apresenta remuneração média 55\% superior à média da indústria de transformação, enquanto o grupo de fabricação de lâmpadas e outros equipamentos de iluminação apresenta remuneração $22 \%$ inferior.

Analisando a remuneração média discriminada entre o pessoal ocupado ligado e nãoligado à produção, também é possível observar disparidades. A remuneração média da indústria total, de transformação e fabricação de máquinas, aparelhos e materiais elétricos brasileira do pessoal ocupado não-ligado à produção é aproximadamente $44 \%$ superior àquela observada ao pessoal ocupado ligado à produção. Em 2007, a remuneração média do pessoal não-ligado à produção era 48\% superior, assim, observa-se redução nesta disparidade.

Outro indicador que importa quando se busca analisar a produtividade da indústria, é a escolaridade média. Busca-se encontrar uma relação positiva entre escolaridade e produtividade. Tratando-se da indústria de transformação, 57,8\% do pessoal ocupado tem ensino médio completo, a média do setor de máquinas, aparelhos e materiais elétricos é semelhante, assim como dos grupos estudados.

Resumindo, ao se analisar aspectos que se relacionam com o pessoal da indústria de fabricação de máquinas, aparelhos e materiais elétricos, o que mais se destaca é o porte médio elevado de alguns grupos industriais, a remuneração média, também mais elevada que a média da indústria de transformação.

4.2 Dados relativos à Produção da Fabricação de máquinas, aparelhos e materiais elétricos

$\mathrm{Na}$ análise dos dados que se relacionam à produção da fabricação de máquinas, aparelhos e materiais elétricos, são verificados: valor bruto da produção industrial (VBPI), valor da transformação industrial (VTI), densidade industrial (VBPI/VTI) total da receita líquida de vendas, custo das operações industriais e produtividade.

Analisando o Valor Bruto da Produção Industrial (VBPI), a fabricação de máquinas, aparelhos e materiais elétricos apresenta participação de 3,1\% na indústria de transformação, em 2013. Dentre os grupos do setor analisado, destacam-se a fabricação de geradores, transformadores e materiais elétricos, 29,8\%, fabricação de equipamentos para distribuição e controle de energia elétrica, 28,4\% e fabricação de eletrodomésticos, 28,6\%, em 2013 (Tabela $5)$.

Tabela 5: Participação no Valor Bruto da Produção Industrial - Indústria total, transformação e Fabricação de máquinas, aparelhos e materiais elétricos e seus grupos (2007 - 2013)

\begin{tabular}{|l|c|c|c|c|c|c|c|}
\hline \multirow{2}{*}{ Total } & $\mathbf{2 0 0 7}$ & $\mathbf{2 0 0 8}$ & $\mathbf{2 0 0 9}$ & $\mathbf{2 0 1 0}$ & $\mathbf{2 0 1 1}$ & $\mathbf{2 0 1 2}$ & $\mathbf{2 0 1 3}$ \\
\cline { 2 - 7 } & $100,0 \%$ & $100,0 \%$ & $100,0 \%$ & $100,0 \%$ & $100,0 \%$ & $100,0 \%$ & $100,0 \%$ \\
\hline C Indústrias de transformação & $94,9 \%$ & $94,9 \%$ & $95,2 \%$ & $94,2 \%$ & $93,9 \%$ & $94,0 \%$ & $94,5 \%$ \\
\hline $\begin{array}{l}\text { 27 Fabricação de máquinas, aparelhos e materiais } \\
\text { elétricos }\end{array}$ & $2,9 \%$ & $3,1 \%$ & $3,5 \%$ & $3,5 \%$ & $3,2 \%$ & $3,2 \%$ & $3,1 \%$ \\
\hline $\begin{array}{l}\text { 27.1 Fabricação de geradores, transformadores e } \\
\text { motores elétricos }\end{array}$ & $25,3 \%$ & $25,8 \%$ & $28,9 \%$ & $26,1 \%$ & $28,4 \%$ & $28,2 \%$ & $29,8 \%$ \\
\hline $\begin{array}{l}\text { 27.2 Fabricação de pilhas, baterias e acumuladores } \\
\text { elétricos }\end{array}$ & $4,1 \%$ & $4,3 \%$ & $3,9 \%$ & $3,8 \%$ & $3,6 \%$ & $3,3 \%$ & $4,0 \%$ \\
\hline $\begin{array}{l}\text { 27.3 Fabricação de equipamentos para distribuição e } \\
\text { controle de energia elétrica }\end{array}$ & $31,0 \%$ & $35,1 \%$ & $26,1 \%$ & $30,1 \%$ & $30,9 \%$ & $30,7 \%$ & $28,4 \%$ \\
\hline $\begin{array}{l}\text { 27.4 Fabricação de lâmpadas e outros equipamentos } \\
\text { de iluminação }\end{array}$ & $3,9 \%$ & $2,6 \%$ & $2,2 \%$ & $2,7 \%$ & $3,0 \%$ & $3,3 \%$ & $2,9 \%$ \\
\hline 27.5 Fabricação de eletrodomésticos & $30,9 \%$ & $26,6 \%$ & $33,0 \%$ & $30,9 \%$ & $26,8 \%$ & $28,5 \%$ & $28,6 \%$ \\
\hline $\begin{array}{l}\text { 27.9 Fabriç̧ão de equipamentos e aparelhos elétricos } \\
\text { não especificados anteriormente }\end{array}$ & $4,9 \%$ & $5,6 \%$ & $5,9 \%$ & $6,3 \%$ & $7,3 \%$ & $6,0 \%$ & $6,4 \%$ \\
\hline
\end{tabular}


Ao se observar o Valor da Transformação Industrial (VTI), a realidade que se verifica no VBPI se repete. A indústria de transformação reduz um pouco sua participação de 93,8\% em 2007 para 90,7\% em 2013. A fabricação de máquinas, aparelhos e materiais elétricos ganha participação ao longo do tempo, de 2,6\% em 2007 para 3,0\% em 2013. Analisando os grupos do setor, destacam-se a fabricação de geradores, transformadores e materiais elétricos, 35,3\%, fabricação de equipamentos para distribuição e controle de energia elétrica, 22,3\% e fabricação de eletrodomésticos, 27,7\%, em 2013 (Tabela 6).

Tabela 6: Participação no Valor da Transformação Industrial - Indústria total, transformação e Fabricação de máquinas, aparelhos e materiais elétricos e seus grupos (2007 - 2013)

\begin{tabular}{|l|c|c|c|c|c|c|c|}
\hline \multirow{2}{*}{ Total } & $\mathbf{2 0 0 7}$ & $\mathbf{2 0 0 8}$ & $\mathbf{2 0 0 9}$ & $\mathbf{2 0 1 0}$ & $\mathbf{2 0 1 1}$ & $\mathbf{2 0 1 2}$ & $\mathbf{2 0 1 3}$ \\
\cline { 2 - 7 } & $100,0 \%$ & $100,0 \%$ & $100,0 \%$ & $100,0 \%$ & $100,0 \%$ & $100,0 \%$ & $100,0 \%$ \\
\hline C Indústrias de transformação & $93,8 \%$ & $93,1 \%$ & $93,5 \%$ & $91,1 \%$ & $90,0 \%$ & $90,1 \%$ & $90,7 \%$ \\
\hline $\begin{array}{l}\text { 27 Fabricação de máquinas, aparelhos e materiais } \\
\text { elétricos }\end{array}$ & $2,6 \%$ & $2,8 \%$ & $3,1 \%$ & $3,1 \%$ & $2,9 \%$ & $3,1 \%$ & $3,0 \%$ \\
\hline $\begin{array}{l}\text { 27.1 Fabricação de geradores, transformadores e } \\
\text { motores elétricos }\end{array}$ & $29,5 \%$ & $28,4 \%$ & $30,5 \%$ & $27,4 \%$ & $29,4 \%$ & $30,9 \%$ & $35,3 \%$ \\
\hline $\begin{array}{l}\text { 27.2 Fabricação de pilhas, baterias e acumuladores } \\
\text { elétricos }\end{array}$ & $3,9 \%$ & $3,8 \%$ & $4,1 \%$ & $3,6 \%$ & $3,2 \%$ & $3,1 \%$ & $3,2 \%$ \\
\hline $\begin{array}{l}\text { 27.3 Fabricação de equipamentos para distribuição e } \\
\text { controle de energia elétrica }\end{array}$ & $24,8 \%$ & $31,3 \%$ & $23,8 \%$ & $26,6 \%$ & $24,7 \%$ & $26,1 \%$ & $22,3 \%$ \\
\hline $\begin{array}{l}\text { 27.4 Fabricação de lâmpadas e outros equipamentos } \\
\text { de iluminação }\end{array}$ & $4,7 \%$ & $2,7 \%$ & $2,5 \%$ & $3,3 \%$ & $3,3 \%$ & $3,9 \%$ & $3,0 \%$ \\
\hline 27.5 Fabricação de eletrodomésticos & $30,8 \%$ & $27,0 \%$ & $32,2 \%$ & $31,6 \%$ & $30,1 \%$ & $28,1 \%$ & $27,7 \%$ \\
\hline $\begin{array}{l}\text { 27.9 Fabricação de equipamentos e aparelhos elétricos } \\
\text { não especificados anteriormente }\end{array}$ & $6,4 \%$ & $6,7 \%$ & $7,0 \%$ & $7,6 \%$ & $9,3 \%$ & $7,9 \%$ & $8,4 \%$ \\
\hline
\end{tabular}

Fonte: PIA - IBGE (2015)

A densidade industrial, mensurada pela relação entre VTI e VBPI, posiciona o quanto é transformado daquilo que é vendido. Como é possível observar na Tabela 7, a densidade da indústria de máquinas, aparelhos e materiais elétricos é inferior aquela observada na indústria total e de transformação, porém, ao se analisar os grupos que compõem o setor, é possível observar grupos mais densos, como é o caso da fabricação de equipamentos e aparelhos elétricos não especificados anteriormente e fabricação de geradores, transformadores e motores elétricos.

Tabela 7: Densidade Industrial (VTI/VBPI) - Indústria total, transformação e Fabricação de máquinas, aparelhos e materiais elétricos e seus grupos (2007 - 2013)

\begin{tabular}{|l|c|c|c|c|c|c|c|}
\hline \multirow{2}{*}{ Total } & $\mathbf{2 0 0 7}$ & $\mathbf{2 0 0 8}$ & $\mathbf{2 0 0 9}$ & $\mathbf{2 0 1 0}$ & $\mathbf{2 0 1 1}$ & $\mathbf{2 0 1 2}$ & $\mathbf{2 0 1 3}$ \\
\hline & 42,5 & 43,5 & 44,2 & 45,6 & 46,1 & 45,3 & 44,8 \\
\hline C Indústrias de transformação & 42,0 & 42,6 & 43,4 & 44,1 & 44,1 & 43,4 & 43,0 \\
\hline 27 Fabricação de máquinas, aparelhos e materiais elétricos & 38,0 & 38,7 & 39,6 & 40,0 & 40,6 & 41,1 & 42,1 \\
\hline 27.1 Fabricação de geradores, transformadores e motores elétricos & 44,3 & 42,7 & 41,7 & 42,0 & 42,0 & 45,0 & 49,9 \\
\hline 27.2 Fabricação de pilhas, baterias e acumuladores elétricos & 36,3 & 34,1 & 42,2 & 38,0 & 36,7 & 38,4 & 34,1 \\
\hline $\begin{array}{l}\text { 27.3 Fabricação de equipamentos para distribuição e controle de } \\
\text { energia elétrica }\end{array}$ & 30,4 & 34,6 & 36,0 & 35,3 & 32,4 & 35,0 & 33,2 \\
\hline 27.4 Fabricação de lâmpadas e outros equipamentos de iluminação & 45,7 & 41,6 & 45,0 & 47,6 & 44,8 & 48,5 & 44,2 \\
\hline 27.5 Fabricação de eletrodomésticos & 37,9 & 39,2 & 38,6 & 40,9 & 45,6 & 40,5 & 40,9 \\
\hline $\begin{array}{l}\text { 27.9 Fabricação de equipamentos e aparelhos elétricos não especificados } \\
\text { anteriormente }\end{array}$ & 50,0 & 46,5 & 46,6 & 47,7 & 51,9 & 54,3 & 55,4 \\
\hline
\end{tabular}

Fonte: PIA - IBGE (2015) 
Para evitar distorções nas comparações, a receita líquida de venda é dividida pelo pessoal ocupado e apresentada na Tabela 8. Assim, a receita liquida da indústria total é superior aquelas observada na indústria de transformação e também na fabricação de máquinas, aparelhos e materiais elétricos. Na análise dos grupos, a fabricação de eletrodomésticos se destaca com receita líquida de vendas superior à da indústria total. Este grupo permite agregação de valor, principalmente através da relação com design, o que pode justificar tal aspecto. Porém, a fabricação de lâmpadas e outros equipamentos de iluminação e fabricação de equipamentos e aparelhos elétricos não especificados anteriormente apresenta receita líquida de vendas bastante inferior àquela observada na indústria total, aproximadamente $60 \%$ do valor.

Tabela 8: Total da receita líquida de vendas (Mil Reais/PO) - Indústria total, transformação e Fabricação de máquinas, aparelhos e materiais elétricos e seus grupos (2007 - 2013)

\begin{tabular}{|l|c|c|c|c|c|c|c|}
\hline \multirow{2}{*}{ Total } & $\mathbf{2 0 0 7}$ & $\mathbf{2 0 0 8}$ & $\mathbf{2 0 0 9}$ & $\mathbf{2 0 1 0}$ & $\mathbf{2 0 1 1}$ & $\mathbf{2 0 1 2}$ & $\mathbf{2 0 1 3}$ \\
\cline { 2 - 7 } & 278,19 & 283,77 & 264,46 & 279,19 & 287,03 & 294,76 & 305,76 \\
\hline C Indústrias de transformação & 269,15 & 274,92 & 257,33 & 269,29 & 277,33 & 285,61 & 297,84 \\
\hline 27 Fabricação de máquinas, aparelhos e materiais elétricos & 262,65 & 286,76 & 274,85 & 303,66 & 275,65 & 282,45 & 275,41 \\
\hline $\begin{array}{l}\text { 27.1 Fabricação de geradores, transformadores e motores } \\
\text { elétricos }\end{array}$ & 264,33 & 287,25 & 314,84 & 315,58 & 291,90 & 298,74 & 293,22 \\
\hline $\begin{array}{l}\text { 27.2 Fabricação de pilhas, baterias e acumuladores } \\
\text { elétricos }\end{array}$ & 208,68 & 228,75 & 208,58 & 211,92 & 193,29 & 204,67 & 228,30 \\
\hline $\begin{array}{l}\text { 27.3 Fabricação de equipamentos para distribuição e } \\
\text { controle de energia elétrica }\end{array}$ & 292,67 & 336,59 & 275,42 & 328,93 & 326,08 & 317,80 & 297,66 \\
\hline $\begin{array}{l}\text { 27.4 Fabricação de lâmpadas e outros equipamentos de } \\
\text { iluminação }\end{array}$ & 196,32 & 148,78 & 131,18 & 160,58 & 154,46 & 172,61 & 166,95 \\
\hline 27.5 Fabricação de eletrodomésticos & 302,55 & 315,31 & 312,29 & 354,93 & 296,66 & 301,19 & 316,40 \\
\hline $\begin{array}{l}\text { 27.9 Fabricação de equipamentos e aparelhos elétricos não } \\
\text { especificados anteriormente }\end{array}$ & 140,36 & 169,63 & 169,48 & 205,13 & 177,54 & 188,84 & 163,22 \\
\hline
\end{tabular}

Fonte: PIA - IBGE (2015)

Cruzando a receita líquida de vendas com o custo das operações industrias (Tabela 9) pode-se ter uma ideia do lucro operacional industrial. Assim, enquanto a indústria total apresenta maior receita líquida de vendas - ao se comparar com a indústria de transformação e fabricação de máquinas, aparelhos e materiais elétricos -, seus custos são inferiores aos da indústria de transformação. A fabricação de geradores, transformadores e motores elétricos apresenta custos inferiores aos da indústria de transformação.

Tabela 9: Custos das operações industriais (Mil Reais/PO) - Indústria total, transformação e Fabricação de máquinas, aparelhos e materiais elétricos e seus grupos (2007 - 2013)

\begin{tabular}{|l|c|c|c|c|c|c|c|}
\hline & $\mathbf{2 0 0 7}$ & $\mathbf{2 0 0 8}$ & $\mathbf{2 0 0 9}$ & $\mathbf{2 0 1 0}$ & $\mathbf{2 0 1 1}$ & $\mathbf{2 0 1 2}$ & $\mathbf{2 0 1 3}$ \\
\cline { 2 - 8 } Total & 150,75 & 151,60 & 135,12 & 140,99 & 141,77 & 145,65 & 153,14 \\
\hline C Indústrias de transformação & 147,20 & 149,09 & 133,18 & 139,44 & 141,28 & 145,34 & 153,43 \\
\hline 27 Fabricação de máquinas, aparelhos e materiais elétricos & 152,38 & 164,05 & 154,00 & 167,36 & 151,58 & 150,90 & 149,96 \\
\hline $\begin{array}{l}\text { 27.1 Fabricação de geradores, transformadores e motores } \\
\text { elétricos }\end{array}$ & 136,20 & 154,90 & 168,27 & 161,79 & 158,83 & 147,51 & 142,11 \\
\hline $\begin{array}{l}\text { 27.2 Fabricação de pilhas, baterias e acumuladores } \\
\text { elétricos }\end{array}$ & 128,09 & 148,05 & 121,69 & 132,47 & 119,86 & 121,54 & 147,25 \\
\hline $\begin{array}{l}\text { 27.3 Fabricação de equipamentos para distribuição e } \\
\text { controle de energia elétrica }\end{array}$ & 195,64 & 204,28 & 166,21 & 197,62 & 202,93 & 194,02 & 184,97 \\
\hline $\begin{array}{l}\text { 27.4 Fabricação de lâmpadas e outros equipamentos de } \\
\text { iluminação }\end{array}$ & 66,80 & 66,99 & 54,87 & 65,56 & 64,78 & 76,14 & 72,87 \\
\hline 27.5 Fabricação de eletrodomésticos & 183,30 & 180,26 & 177,83 & 200,92 & 150,47 & 161,35 & 177,17 \\
\hline $\begin{array}{l}\text { 27.9 Fabricação de equipamentos e aparelhos elétricos não } \\
\text { especificados anteriormente }\end{array}$ & 66,56 & 87,30 & 84,67 & 92,67 & 79,95 & 71,77 & 66,01 \\
\hline
\end{tabular}

Fonte: PIA - IBGE (2015) 
Dentre a análise dos grupos, a fabricação de lâmpadas e outros equipamentos de iluminação assim como fabricação de equipamentos e aparelhos elétricos não especificados anteriormente apresentam custos bem reduzidos, assim, se entende suas receitas líquidas de vendas, também reduzidas. O grupo com maior custo é o de fabricação de equipamentos para distribuição e controle de energia elétrica e fabricação de eletrodomésticos, superior ao da indústria de transformação. Dentre os grupos, fabricação de geradores, transformadores e motores elétricos, fabricação de pilhas, baterias e acumuladores elétricos, fabricação de lâmpadas e outros equipamentos de iluminação aumentaram seus custos de 2007 para 2013, assim como a indústria total e de transformação.

Ao se observar a produtividade das indústrias e grupos industrias, Tabela 10, observa-se a produtividade da indústria de transformação inferior à da indústria total e superior à fabricação de máquinas, aparelhos e materiais elétricos. Porém, a fabricação de geradores, transformadores e motores elétricos se destaca com produtividade superior àquela observada na indústria total, os outros grupos industriais apresentam produtividade inferior. Em todos os grupos industriais assim como indústria total, de transformação e fabricação de máquinas, aparelhos e materiais elétricos, a produtividade subiu de 2007 a 2013.

Tabela 10: Produtividade da Indústria (VTI/PO) Indústria total, transformação e Fabricação de máquinas, aparelhos e materiais elétricos e seus grupos (2007 - 2013)

\begin{tabular}{|l|c|c|c|c|c|c|c|}
\hline \multirow{2}{*}{ Total } & $\mathbf{2 0 0 7}$ & $\mathbf{2 0 0 8}$ & $\mathbf{2 0 0 9}$ & $\mathbf{2 0 1 0}$ & $\mathbf{2 0 1 1}$ & $\mathbf{2 0 1 2}$ & $\mathbf{2 0 1 3}$ \\
\cline { 2 - 7 } & 111,26 & 116,59 & 107,00 & 118,34 & 121,09 & 120,64 & 124,52 \\
\hline C Indústrias de transformação & 106,52 & 110,82 & 102,21 & 110,16 & 111,67 & 111,61 & 115,89 \\
\hline 27 Fabricação de máquinas, aparelhos e materiais elétricos & 93,45 & 103,67 & 100,78 & 111,54 & 103,74 & 105,23 & 109,17 \\
\hline $\begin{array}{l}\text { 27.1 Fabricação de geradores, transformadores e motores } \\
\text { elétricos }\end{array}$ & 108,26 & 115,36 & 120,48 & 117,06 & 115,09 & 120,57 & 141,71 \\
\hline $\begin{array}{l}\text { 27.2 Fabricação de pilhas, baterias e acumuladores } \\
\text { elétricos }\end{array}$ & 73,04 & 76,60 & 88,88 & 81,21 & 69,50 & 75,86 & 76,28 \\
\hline $\begin{array}{l}\text { 27.3 Fabricação de equipamentos para distribuição e } \\
\text { controle de energia elétrica }\end{array}$ & 85,33 & 107,95 & 93,33 & 107,70 & 97,48 & 104,48 & 91,77 \\
\hline $\begin{array}{l}\text { 27.4 Fabricação de lâmpadas e outros equipamentos de } \\
\text { iluminação }\end{array}$ & 56,31 & 47,66 & 44,89 & 59,57 & 52,64 & 71,84 & 57,70 \\
\hline 27.5 Fabricação de eletrodomésticos & 111,97 & 116,24 & 111,66 & 139,08 & 126,18 & 109,63 & 122,41 \\
\hline $\begin{array}{l}\text { 27.9 Fabricação de equipamentos e aparelhos elétricos não } \\
\text { especificados anteriormente }\end{array}$ & 66,60 & 75,85 & 73,78 & 84,39 & 86,25 & 85,16 & 81,95 \\
\hline
\end{tabular}

Fonte: PIA - IBGE (2015)

Ao se analisar aspectos de produção da indústria de fabricação de máquinas, aparelhos e materiais elétricos observa-se que o setor tem produtividade inferior àquela observada na indústria de transformação. Os custos também são inferiores, assim como a receita líquida de vendas. A densidade industrial é também inferior. Porém, a realidade ao se analisar os grupos que compõem o setor se altera, destaca-se o grupo de fabricação de geradores, transformadores e motores elétricos e fabricação de eletrodomésticos, que apresentam lógica diferenciadas e, muitas vezes, superior à da indústria de transformação e total.

4.3 Dados relativos ao Investimento e Inovação da Fabricação de máquinas, aparelhos e materiais elétricos

O investimento será analisado observando a aquisição e melhorias no ativo imobilizado industrial, enquanto para a inovação, verifica-se o dispêndio das empresas com atividades de inovação, a proporção das empresas que inovaram e as inovações de produto e processo. Para investimento, observa-se dados de 2007 a 2013, enquanto para inovação, 
exceto o dispêndio que é somente para o ano de 2011, os demais aspectos são agregados de 2009 a 2011.

Tabela 11: Ativo imobilizado - aquisições - valor (Mil Reais/PO) - Indústria total, transformação e Fabricação de máquinas, aparelhos e materiais elétricos e seus grupos (2007 - 2013)

\begin{tabular}{|l|c|c|c|c|c|c|c|}
\hline & $\mathbf{2 0 0 7}$ & $\mathbf{2 0 0 8}$ & $\mathbf{2 0 0 9}$ & $\mathbf{2 0 1 0}$ & $\mathbf{2 0 1 1}$ & $\mathbf{2 0 1 2}$ & $\mathbf{2 0 1 3}$ \\
\cline { 2 - 7 } Total & 20,92 & 21,45 & 19,44 & 19,75 & 20,57 & 23,92 & 24,23 \\
\hline C Indústrias de transformação & 19,12 & 20,23 & 18,32 & 18,61 & 18,57 & 20,21 & 20,93 \\
\hline 27 Fabricação de máquinas, aparelhos e materiais elétricos & 10,63 & 9,40 & 10,16 & 9,38 & 10,33 & 10,62 & 9,13 \\
\hline $\begin{array}{l}\text { 27.1 Fabricação de geradores, transformadores e motores } \\
\text { elétricos }\end{array}$ & 13,77 & 11,91 & 12,14 & 8,27 & 10,67 & 12,10 & 11,68 \\
\hline 27.2 Fabricação de pilhas, baterias e acumuladores elétricos & 11,36 & 8,01 & 5,15 & 7,55 & 15,38 & 13,51 & 13,26 \\
\hline $\begin{array}{l}\text { 27.3 Fabricação de equipamentos para distribuição e controle } \\
\text { de energia elétrica }\end{array}$ & & & & & & & \\
\hline $\begin{array}{l}\text { 27.4 Fabricação de lâmpadas e outros equipamentos de } \\
\text { iluminação }\end{array}$ & $\mathbf{4 , 5 3}$ & 9,71 & 15,33 & 10,90 & 8,67 & 13,32 & 9,28 \\
\hline 27.5 Fabricação de eletrodomésticos & 3,38 & 5,64 & 5,15 & 3,46 & 3,47 & 3,07 \\
\hline $\begin{array}{l}\text { 27.9 Fabricação de equipamentos e aparelhos elétricos não } \\
\text { especificados anteriormente }\end{array}$ & $\mathbf{2 1 3 , 4 2}$ & $\mathbf{9 , 3 2}$ & 7,35 & 11,38 & 14,39 & 8,38 & 8,63 \\
\hline
\end{tabular}

Fonte: PIA - IBGE (2015)

Conforme Tabela 11, verifica-se que o investimento em ativo imobilizado cresce de 2007 a 2013 na indústria total e de transformação, porém, decresce na fabricação de máquinas, aparelhos e materiais elétricos. Outro aspecto que chama a atenção é que, mesmo normalizando pelo pessoal ocupado, as aquisições de ativo imobilizado do setor são inferiores àquelas observadas na indústria total e de transformação. Dentre os grupos que compõem o setor, os valores mais elevados de aquisições de ativos imobilizados são da fabricação de geradores, transformadores e motores elétricos e fabricação de pilhas, baterias e acumuladores elétricos.

Tabela 12: Ativo imobilizado - melhorias - valor (Mil Reais/PO) - Indústria total, transformação e Fabricação de máquinas, aparelhos e materiais elétricos e seus grupos (2007 - 2013)

\begin{tabular}{|l|c|c|c|c|c|c|c|}
\hline Ativo imobilizado - melhorias - valor (Mil Reais) & $\mathbf{2 0 0 7}$ & $\mathbf{2 0 0 8}$ & $\mathbf{2 0 0 9}$ & $\mathbf{2 0 1 0}$ & $\mathbf{2 0 1 1}$ & $\mathbf{2 0 1 2}$ & $\mathbf{2 0 1 3}$ \\
\hline & 0,93 & 0,96 & 1,35 & 1,22 & 0,78 & 0,62 & 0,67 \\
\hline Total & 0,91 & 0,94 & 1,32 & 1,22 & 0,79 & 0,62 & 0,67 \\
\hline C Indústrias de transformação & 0,48 & 0,31 & 0,29 & 0,59 & 0,57 & 0,61 & 0,40 \\
\hline 27 Fabricação de máquinas, aparelhos e materiais elétricos & 0,05 & 0,30 & 0,42 & 0,31 & 0,30 & 1,49 & 0,10 \\
\hline 27.1 Fabricação de geradores, transformadores e motores elétricos & 0,64 & 0,10 & 0,04 & 0,04 & 0,00 & 0,11 & 0,08 \\
\hline 27.2 Fabricação de pilhas, baterias e acumuladores elétricos & & & & & & & \\
\hline $\begin{array}{l}\text { 27.3 Fabricação de equipamentos para distribuição e controle de } \\
\text { energia elétrica }\end{array}$ & 0,99 & 0,39 & 0,20 & 1,12 & 0,35 & 0,29 & 1,01 \\
\hline 27.4 Fabricação de lâmpadas e outros equipamentos de iluminação & 0,08 & 0,09 & 0,26 & 0,29 & 0,30 & 0,14 & 0,11 \\
\hline 27.5 Fabricação de eletrodomésticos & 0,22 & 0,35 & 0,24 & 0,15 & 1,16 & 0,23 & 0,24 \\
\hline $\begin{array}{l}\text { 27.9 Fabricação de equipamentos e aparelhos elétricos não } \\
\text { especificados anteriormente }\end{array}$ & 1,16 & 0,27 & 0,48 & 1,44 & 0,78 & 0,61 & 0,36 \\
\hline
\end{tabular}

Fonte: PIA - IBGE (2015)

Analisando o investimento em termos de melhorias no ativo imobilizado, o comportamento da indústria é distinto (Tabela 12). Tratando-se da indústria total, transformação assim como da fabricação de máquinas, aparelhos e materiais elétricos, observa-se decréscimo da implementação de melhorias. O setor analisado também apresenta média de implementação de melhorias inferior às observadas na indústria nacional. Importa ressaltar que o investimento, tanto aquisições quanto melhorias, não apresenta tendência clara, 
isso pois tem característica de se concentrar em anos determinados, uma vez que após um alto investimento a empresa fica um período desfrutando de seus ganhos de produtividade, planejando e se capitalizando para investimentos futuros.

Tabela 13: Empresas que inovaram, inovações em produto e processo e Dispêndio com inovação (dividido pelo número de empresas) (2009 - 2011, 2011)

\begin{tabular}{|c|c|c|c|c|c|c|c|}
\hline & \multirow{2}{*}{$\%$} & \multicolumn{4}{|c|}{$\begin{array}{l}\text { Dispêndios realizados pelas empresas } \\
\text { inovadoras nas atividades inovativas } \\
(2011)\end{array}$} & \multicolumn{2}{|c|}{$\begin{array}{c}\text { Empresas que } \\
\text { implementaram inovação }\end{array}$} \\
\hline & & \begin{tabular}{|c|}
$\begin{array}{c}\text { Número } \\
\text { de } \\
\text { empresas }\end{array}$ \\
\end{tabular} & $\begin{array}{c}\text { Valor } \\
(1000 \\
\text { R\$) } \\
\end{array}$ & $\begin{array}{c}\text { Número } \\
\text { de } \\
\text { empresas }\end{array}$ & $\begin{array}{c}\text { Valor } \\
(1000 \\
\text { R\$) } \\
\end{array}$ & $\%$ & $\%$ \\
\hline & 2009-2011 & \multicolumn{2}{|c|}{ Total } & \multicolumn{2}{|c|}{\begin{tabular}{|c|} 
Atividades internas \\
de \\
Pesquisa e \\
Desenvolvimento \\
\end{tabular}} & De produto & De processo \\
\hline Total & 71,1 & 20,2 & 358,14 & 4,1 & 110,18 & 12,85 & 22,53 \\
\hline Indústrias de transformação & 64,2 & 18,1 & 281,97 & 3,3 & 82,80 & 11,25 & 20,53 \\
\hline $\begin{array}{l}\text { Fabricação de máquinas, } \\
\text { aparelhos e materiais elétricos }\end{array}$ & 76,1 & 27,1 & 627,17 & 10,2 & 228,64 & 23,02 & 30,79 \\
\hline $\begin{array}{l}\text { Fabricação de geradores, } \\
\text { transformadores e } \\
\text { equipamentos para distribuição } \\
\text { de energia elétrica }\end{array}$ & 83,4 & 26,3 & 689,26 & 9,7 & 372,52 & 27,47 & 30,04 \\
\hline Fabricação de eletrodomésticos & 76,0 & 43,1 & 2074,12 & 33,3 & 458,44 & 20,85 & 40,63 \\
\hline $\begin{array}{l}\text { Fabricação de pilhas, lâmpadas } \\
\text { e outros aparelhos elétricos }\end{array}$ & 69,6 & 24,3 & 246,00 & 5,6 & 47,57 & 19,50 & 29,25 \\
\hline
\end{tabular}

Fonte: PINTEC - IBGE (2015)

A análise da inovação aponta que o setor apresenta taxa de inovação superior àquela observada na indústria total e de transformação (Tabela 13). De 2009 a 2011, 76,1\% das empresas do setor inovaram, enquanto para a indústria total e de transformação este número foi de 71,1 e 64,2\%, respectivamente. O dispêndio com inovação também foi superior, com destaque para a fabricação de eletrodomésticos. O valor dispendido com pesquisa e desenvolvimento também é superior, exceto na fabricação de pilhas, lâmpadas e outros aparelhos elétricos. A metodologia da PINTEC agrupa alguns grupos, assim sendo estes diferentes àqueles observados na PIA.

O número de empresas que implementou inovação de produto também é superior às taxas da indústria total e de transformação, 23\%, em comparação a 12,8 e 11,2\%, respectivamente. Dentre os grupos, destaca-se a fabricação de geradores, transformadores e equipamentos para distribuição de energia elétrica, na inovação de produto e fabricação de máquinas, aparelhos e materiais elétricos, de processos.

Apesar do desempenho inferior em termos de investimento, aquisição ou melhorias de ativos imobilizados, a fabricação de máquinas, aparelhos e materiais elétricos tem se destacado nos números de inovação. Tanto a porcentagem de empresas inovadoras quando dispêndio com inovação e implementação de inovação de produto e processo seus dados são superiores aos da indústria total e de transformação.

5. CONCLUSÃO: análise da produtividade no setor de Fabricação de máquinas, aparelhos e materiais elétricos

A produtividade do setor de máquinas, aparelhos e materiais elétricos demonstrou-se inferior àquela observada na indústria total e de transformação, é possível observar bastante 
variabilidade entre a produtividade dos grupos que compõem o setor, inclusive, com a produtividade da fabricação de geradores, transformadores e motores elétricos superior à produtividade média da indústria nacional.

Apesar de ser uma referência, a comparação da produtividade do setor com a média da indústria total e de transformação nem sempre traz os melhores resultados, sendo que o setor apresenta dinâmica própria e diferenciada. O setor, internamente, apresenta também lógica bastante distinta, enquanto a fabricação de eletrodomésticos e lâmpadas e outros equipamentos de iluminação apresenta alto potencial de diversificação e agregação de valor por meio da relação de setores como de design e marketing, a fabricação de geradores, transformadores e motores elétricos ou de equipamentos para distribuição e controle de energia elétrica já apresenta dinâmica competitiva diferenciada, nestes termos.

Mesmo normalizando pelo pessoal ocupado, o setor apresenta investimento em aquisição e modernização de ativos imobilizados inferior aos observados na indústria, inclusive analisando seus grupos industriais. O setor apresenta características de investimentos mais perenes que o observado em outros setores onde o ativo imobilizado é de menor complexidade, o que pode justificar parcialmente o baixo investimento.

Chama a atenção os resultados de inovação, nos quais o setor de fabricação de máquinas, aparelhos e materiais elétricos se destaca. Das empresas do setor, de 2009 a 2011, $76 \%$ inovaram, percentual superior às médias da indústria nacional e de transformação. Nos outros dados de inovação, o setor também se destacou. $\mathrm{O}$ setor tem investido em pesquisa e desenvolvimento e implementado inovações de produto e processos.

Assim, ao se comparar produtividade e inovação na indústria nacional, de transformação e do setor estudado, em um primeiro momento parece que a relação carece de lógica. Porém, os setores apresentam dinâmicas distintas, é importante, desta forma, comparar tais dados com outros países, dentro de um mesmo recorte setorial, ou verificando os complexos da indústria de fabricação de máquinas, aparelhos e materiais elétricos dos estados brasileiros, visando não tirar conclusões precipitadas.

\section{REFERÊNCIAS}

MALERBA, F.; ORSENIGO, L. Technological Regimes and Sectoral Patterns of Innovative Activities. Oxford Jornals, vol 6, n. ${ }^{\circ}$ 1, 2006, p. 83-118.

DOSI, G. Opportunities; incentives and the collective patterns of technological change. The Economic Journal, nº107, p. 1530-1547, set., 1998.

NELSON, R. R. e WINTER, S. G. An evolutionary theory af economic change. Estados Unidos: Harvard U. P, 1982.

STEINGRABER, Ronivaldo. INOVAÇÃO E PRODUTIVIDADE: O PAPEL DOS SISTEMAS DE INOVAÇÃO PARA A INDÚSTRIA BRASILEIRA. 2009. 217 f. Tese (Doutorado) - Curso de Economia, Ufpr, Cutiriba, 2009.

IBGE - Pesquisa Industrial Anual - PIA - 2015

IBGE - Pesquisa Industrial da Inovação Tecnológica - PINTEC - 2015 
